\title{
Investigation on mechanical properties of basalt composite fabrics(experiment study)
}

\author{
H.Talebi.Mazraehshahi ${ }^{1, \mathrm{a}}$ and H.Zamani ${ }^{2}$ \\ ${ }^{1}$ Aerosapce Engineering Department, Sharif University Of Technology, Tehran, Iran \\ ${ }^{2}$ Mechanical Engineering Department, Isfahan University of Technology, Isfahan, Iran
}

\begin{abstract}
To fully appreciate the role and application of composite materials to structures, correct understanding of mechanical behaviors required for selection of optimum material. Fabric reinforced composites are composed of a matrix that is reinforced with pliable fabric, glass fabric is most popular reinforcement for different application specially in aircraft structure, although other fabric material are also used. At this study new fabric material called basalt with epoxy resin introduced and mechanical behaviors of this material investigated from view point of testing. For this study two type of fabric with different thickness used. Comparison between this composite reinforcement with popular reinforcement as carbon, glass, kevlar performed.

To determine mechanical properties of epoxy based basalt fabric following test procedure performed :
\end{abstract}

1). Tensile testing according to ASTM D3039 in $0^{\circ}$ and $90^{\circ}$ direction to find ultimate strength in tension and shear, modulus of elasticity, elangation and ultimate strain.

2). Compression testing according to EN 2850 ultimate compression strength and maximum deformation under compression loading.

3). Shear testing according to ASTM D3518-94 to find in plane shear response of polymer matrix composites materials.

4). Predict flexural properties of sandwich construction which manufactured from basalt facing with PVC foam core according to ASTM C393-94.

Material strength properties must be based on enough tests of material to meet the test procedure specifications [1]. For this reason six specimens were manufactured for testing and the tests were performed on them using an INSTRON machine model 5582. In the study, the effect of percent of resin in basalt reinforced composite was investigated. Also the weights of the ballast based composites with different percent of resin were measured with conventional composites. As the weight is an important parameter in aerospace industry when the designer wants to replace one material with another, the effect of weight must be considered. Weight measurement showed that the replacement of glass fabric reinforcement with basalt fabric has little effect on weight.

\footnotetext{
a e-mail : h_talebi@alum.sharif.edu
} 
Investigation also shows that mechanical behavior of basalt fabric is higher than glass fabric. This is due to the excellent mechanical properties of the ballast fabric such as Young modulus and strength in compare with the glass fabric. Figure1 shows the samples which used for tensile testing in warp direction.

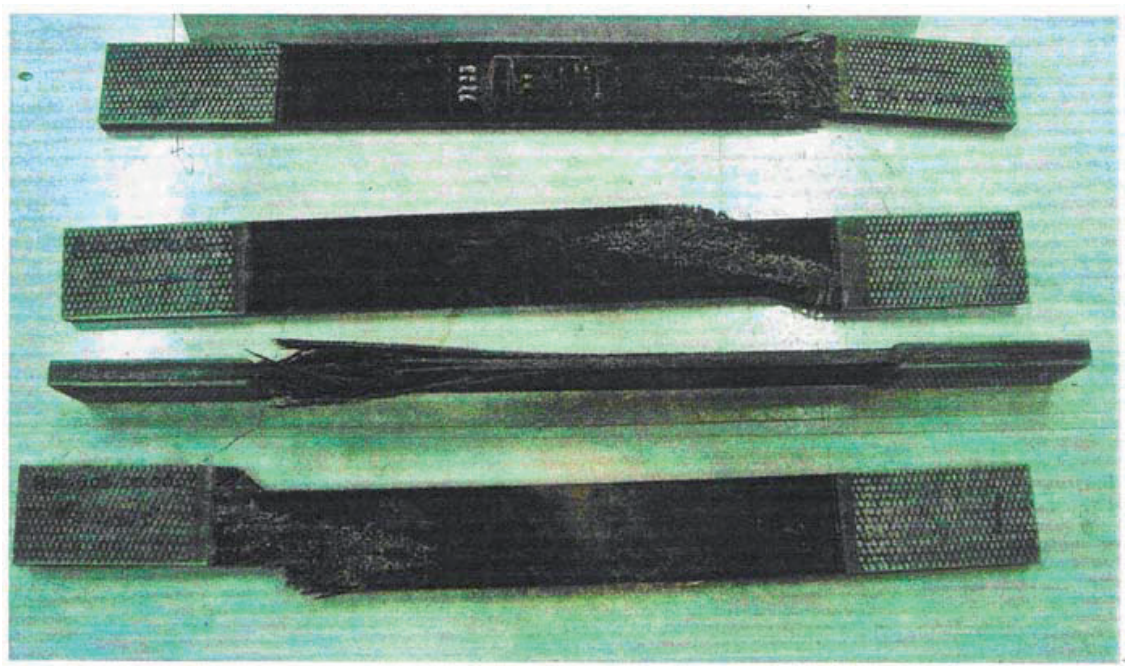

Fig.1. Samples which used for tensile testing in warp direction after failure

\section{References}

1. John S. Tomblin, Material qualification and equivalency of polymer matrix composite material systems DOT/FAA/AR-00/47, April 2001 